\title{
Inter-hospital variations in caesarean sections. A risk adjusted comparison in the Valencia public hospitals
}

\author{
Julian Librero, Salvador Peiró, Soledad Márquez Calderón
}

\begin{abstract}
Background-The aim of this study was to describe the variability in caesarean rates in the public hospitals in the Valencia Region, Spain, and to analyse the association between caesarean sections and clinical and extra-clinical factors.

Methods-Analysis of data contained in the Minimum Basic Data Set (MBDS) compiled for all births in 11 public hospitals in Valencia during 1994-1995 $(n=36$ 819). Bivariate and multivariate analyses were used to evaluate the association between caesarean section rates and specific risk factors. The multivariate model was used to construct predictions about caesarean rates for each hospital, for comparison with rates observed.

Results-Caesarean rates were $17.6 \%$ (inter-hospital range: $14.7 \%$ to $25.0 \%$ ), with ample variability between hospitals in the diagnosis of maternal-fetal risk factors (particularly dystocia and fetal distress), and the indication for caesarean in the presence of these factors. Multivariate analysis showed that maternal-fetal risk factors correlated strongly with caesarean section, although extra-clinical factors, such as the day of the week, also correlated positively. After adjusting for the risk factors, the inter-hospital variation in caesarean rates persisted.
\end{abstract}

Conclusions-Although certain limitations (imprecision of some diagnoses and information biases in the MBDS) make it impossible to establish unequivocal conclusions, results show a high degree of variability among hospitals when opting for caesarean section. This variability cannot be justified by differences in obstetric risks.

(F Epidemiol Community Health 2000;54:631-636)

Pública, Spain

J Librero

S Peiró

Fundación Instituto de Investigación en Servicios de Salud, Spain

J Librero

S Peiró

S Márquez Calderón

Correspondence to: Dr Peiró, Instituto

Valenciano de Estudios en

Salud Pública, Juan de Garay

21, 46017 Valencia, Spain

(peiro_bor@gva.es)

Accepted for publication 28 March 2000 tored this "epidemic", concluding almost unanimously that differences in maternal-fetal risk justify neither the incidence of caesareans, nor the differences in rates observed.

Three lines of research have undertaken to clarify the variations observed in caesarean section rates. The aim of the first has been to uncover a generalised overuse of surgery, and the corresponding overexposure to the risks involved. Most of these studies argue that a large percentage of caesarean sections are unnecessary, and place optimum rates for positive effects on maternal and perinatal mortality at around $7-12 \%$ of births. ${ }^{78}$ The second line has attempted to identify non-clinical factors associated with caesarean sections, and establish their relative importance. Finally, the third group has concentrated on evaluating the effects of measures taken to reverse the upward trend in caesareans.

In Spain little has been published on the subject, and until the release of the Survey of Health Establishments for 1984-1988, no data were available on the incidence of caesareans. ${ }^{9}$ During the period covered by the survey, caesareans rose from $9.4 \%$ to $12.9 \%$ of births ( $9.7 \%$ to $13.6 \%$ in the Valencia Region), with private hospitals reaching 2-3 points above the average. More recent data indicate that the trend continues to rise. ${ }^{10}$ Figures, however, present only general rates, with no breakdown of the motives behind the decision to operate. This makes it impossible to determine to what extent, if at all, the variability observed is justified by varying risks within the populations treated. The aim of this study was to describe the variability in caesarean rates in the public hospitals of Valencia in 1994-1995, taking into account differences in obstetric risks in the populations treated, and to analyse the association between caesarean section rates and specific clinical and non-clinical factors.

\section{Methods}

SETTING

The study was conducted in the hospitals administered by the Valencia Health Service (VHS), the health system managed by the Valencia Regional Government. This network provides health care for the 3.9 million inhabitants of the Region, and comprises over 8000 beds ( $80 \%$ of those available in the region). Among the noteworthy features of the VHS are universal coverage, the cost free status of care, hospital funding through a general budget and payment by salary of the doctors, who have semi-civil servant status and receive no further monetary incentives.
SOURCE OF DATA AND SAMPLE

The Minimum Basic Data Set (MBDS), is an exhaustive database of all hospitalisation episodes in the VHS. It contains 30 variables, five corresponding to diagnostics (nine since 1995), and four to procedures (nine since 
Table 1 Obstetric risk factors. Hierarchical classification of indications for caesarean

\begin{tabular}{lll}
\hline Category & Description & ICD-9-CM \\
\hline Breech & Breech presentation & 652.2 \\
Dystocia & Materno-fetal disproportion & 653 \\
& Obstructed birth & 660 \\
& Abnormal uterine contractions & 661 (except 661.3$)$ \\
& Prolonged labour & 662 \\
& Abnormal presentation & 652 (except $652.1,652.5)$ \\
Fetal distress & Failure in induction of labour & $659.0 / 659.1$ \\
& Fetal distress & 656.3 \\
Other & Prolapsed cord & 663.0 \\
& Antepartum haemorrhage, abruptio placenta and previa placenta & 641 \\
& Insufficient or excessive fetal growth & $656.5 / 656.6$ \\
& Genital herpes & $647.6 / 54$ \\
& Diabetes mellitus/abnormal glucose tolerance & $648.0 / 648.8$ \\
& Arterial hypertension & 642 \\
& Oligohydramnios & 658.0 \\
& Infection of amniotic cavity & 658.4 \\
& Malformation of fetal SNC & 655.0 \\
& Congenital/acquired abnormality of cervix or vagina & $654.6 / 654.7$ \\
& Iso-immunisation with Rh antigen & 656.1 \\
Remainder abnormal births & $430,431,432,433,434$ \\
& Cerebral occlusion-haemorrhage & Remainder of births not coded under code 650 (completely normal birth) or coded under V27.0 \\
& (newborns), 670 to 676 (complications during puerperium) or 654.2 (previous caesarean)
\end{tabular}

1995), all coded according to the International Classification of Diseases Review 9 Clinical Modification (ICD9CM). In the 18 hospitals using the MBDS in 1994-95, 50550 hospitalisations ended in birth (Diagnosis Related Groups (DRG): 370 to 375; ICD9CM: 650 to 669). Of these, 13239 cases, corresponding to six hospitals, were excluded to minimise biases attributable to poor quality information on the

Table 2 Obstetric risk factors. Valencia hospitals, years 1994-95

\begin{tabular}{|c|c|c|c|}
\hline Condition & Number & $\%$ of total & $\%$ caesareans \\
\hline Antecedent of caesarean & 1522 & 4.1 & 72.7 \\
\hline Breech presentation & 1090 & 3.0 & 70.3 \\
\hline Dystocia & 2985 & 8.1 & 85.9 \\
\hline Fetal distress & 3086 & 8.4 & 35.2 \\
\hline Other or maternal factors ${ }^{\star}$ (all) & 1639 & 4.4 & 41.1 \\
\hline $\begin{array}{l}\text { Antepartum haemorrhaging, abruptio and } \\
\text { others (641) }\end{array}$ & 190 & 0.5 & 85.6 \\
\hline Delayed intrauterine growth (656.5) & 96 & 0.3 & 46.9 \\
\hline Macrosomatia (656.6) & 54 & 0.1 & 37.0 \\
\hline Diabetes mellitus $(648.0,648.8)$ & 191 & 0.5 & 25.6 \\
\hline Hypertension disease (642) & 364 & 1.0 & 47.0 \\
\hline Oligohydramnios (658.0) & 74 & 0.2 & 28.7 \\
\hline Abnormal uterine neck (654.6) & 138 & 0.4 & 99.3 \\
\hline $\mathrm{Rh}$ iso-immunisation (656.1) & 481 & 1.3 & 8.9 \\
\hline Abnormal rests after birth (diagnosis 650 ) & 7472 & 20.3 & 14.4 \\
\hline Multiple birth (g) & 521 & 1.4 & 52.2 \\
\hline \multicolumn{4}{|l|}{ Weight at birth } \\
\hline less than 2500 & 5925 & 16.1 & 22.6 \\
\hline between 2500 and 4000 & 28143 & 76.4 & 15.3 \\
\hline greater than 4000 & 1580 & 4.3 & 26.6 \\
\hline not provided or invalid & 1171 & 3.2 & 34.7 \\
\hline \multicolumn{4}{|l|}{ Maternal age (y) } \\
\hline less than 25 & 5372 & 14.6 & 14.9 \\
\hline under 25 and 34 & 26246 & 71.3 & 17.1 \\
\hline more than 34 & 5027 & 13.6 & 23.1 \\
\hline not provided or invalid & 174 & 0.5 & 16.1 \\
\hline \multicolumn{4}{|l|}{ Charlson Comorbidity Index 854} \\
\hline 0 (no chronic comorbidity) & 36566 & 99.3 & 17.4 \\
\hline 1 or more & 253 & 0.7 & 41.5 \\
\hline \multicolumn{4}{|l|}{ Circumstances of admission } \\
\hline Emergency & 36330 & 98.7 & 17.5 \\
\hline Programmed & 487 & 1.3 & 27.3 \\
\hline Not provided or invalid & 2 & 0.0 & 100.0 \\
\hline \multicolumn{4}{|l|}{ Length of prepartal stay (days) } \\
\hline 0 & 21465 & 58.3 & 12.7 \\
\hline 1 & 8937 & 24.3 & 18.5 \\
\hline 2 & 1757 & 4.8 & 26.5 \\
\hline 3 & 1095 & 3.0 & 28.4 \\
\hline 4 or more & 2951 & 8.0 & 42.2 \\
\hline not provided or invalid & 614 & 1.7 & 12.4 \\
\hline \multicolumn{4}{|l|}{ Day of the week } \\
\hline Weekend & 9428 & 25.6 & 14.7 \\
\hline Monday-Friday & 26878 & 73.0 & 18.7 \\
\hline Not provided or invalid & 513 & 1.4 & 12.3 \\
\hline Total & 36819 & 100.0 & 17.6 \\
\hline
\end{tabular}

*In the group "Other maternal or fetal factors", no breakdown is provided for groups with an incidence lower than 1 per 1000 births, such as malformation of the SNC or genital herpes, although these are computed in the total.
MBDS, as $20 \%$ lacked information or contained errors in relevant variables (birth date, admission date and delivery date and newborn's weight); another 492 cases corresponding to a seventh hospital were eliminated because of an unreasonable percentage of multiple deliveries, leaving for analysis 36819 hospitalisations ending in birth in 11 hospitals.

\section{DEFINITIONS AND VARIABLES}

The following variables and definitions were used: (a) clinical factors not necessarily indicative of cesarean section: age (below 14 and over 50 were considered erroneous); weight at birth in grams (for the firstborn in multiple deliveries, erroneous $<600 \mathrm{~g}$ ); comorbidity, measured as presence or absence of any comorbidity included in an adaptation of the Charlson Index for administrative databases ${ }^{11}$; previous caesarean section, identified with the ICD9CM code 654.2 or indicated on previous births; multiple pregnancy, identified in the variables sex or weight of the second born or the ICD9CM code 651. (b) Clinical factors suggesting maternal-fetal risk: we used a modified version of the classification proposed by Anderson and Lomas, ${ }^{12}$ validated for databases, ${ }^{13}$ to construct the variable maternalfetal risk. It included five hierarchical categories (table 1): presentation in breech position, dystocia, fetal distress, other maternal or fetal risk factors, and other abnormal deliveries. (c) Ambiguous clinical factors: length of stay before delivery; emergency or programmed admission. (d) Non-clinical factors: day of birth, grouped as weekday or weekend; and hospital.

MAIN OUTCOME MEASURED

Performance of any type of caesarean section: classic, lower cervical or extraperitoneal (DRG: 370-371; ICD9CM: 74).

ANALYSIS

Firstly, a bivariate analysis was conducted to describe the incidence of caesarean sections in relation to various circumstances. The distribution of the risk factors and the probability of caesarean section were analysed on a hospital 
Table 3 Percentage of births and risk births by hospital and percentage of caesareans by type of risk

\begin{tabular}{|c|c|c|c|c|c|c|c|c|c|c|}
\hline \multirow[b]{2}{*}{ Hospital } & \multicolumn{2}{|l|}{ Total } & \multicolumn{2}{|l|}{ Breech } & \multicolumn{2}{|l|}{ Dystocia } & \multicolumn{2}{|c|}{ Fetal distress } & \multicolumn{2}{|c|}{ Antec. caesarean } \\
\hline & Births & $\%$ c-section & $\%$ Breech & $\%$ c-section & \% Dystocia & $\%$ c-section & $\%$ Distress & $\%$ c-section & $\%$ Antec. & $\%$ c-section \\
\hline $\mathrm{A}$ & 3407 & 21.31 & 2.23 & 76.32 & 11.62 & 93.18 & 2.88 & 82.65 & 2.26 & 97.40 \\
\hline B & 3206 & 14.69 & 1.62 & 61.54 & 6.67 & 91.59 & 2.28 & 86.30 & 2.78 & 92.13 \\
\hline $\mathrm{C}$ & 1920 & 17.55 & 2.03 & 87.18 & 6.41 & 90.24 & 1.88 & 69.44 & 2.19 & 97.62 \\
\hline $\mathrm{D}$ & 13539 & 19.31 & 4.53 & 65.91 & 7.78 & 97.53 & 14.98 & 27.86 & 6.71 & 62.33 \\
\hline $\mathrm{E}$ & 1607 & 16.49 & 3.05 & 89.80 & 6.41 & 96.12 & 2.55 & 87.80 & 1.93 & 100.00 \\
\hline $\mathrm{F}$ & 2422 & 15.15 & 2.97 & 87.50 & 7.72 & 60.96 & 6.69 & 66.05 & 3.43 & 61.45 \\
\hline G & 565 & 24.96 & 1.77 & 90.00 & 18.76 & 47.17 & 10.97 & 95.16 & 2.65 & 93.33 \\
\hline $\mathrm{H}$ & 2698 & 16.05 & 2.37 & 70.31 & 7.64 & 97.09 & 16.05 & 7.39 & 4.78 & 93.02 \\
\hline I & 1550 & 15.16 & 2.45 & 84.21 & 13.10 & 43.35 & 4.97 & 66.23 & 2.97 & 89.13 \\
\hline $\mathrm{J}$ & 4214 & 14.67 & 1.47 & 62.90 & 6.34 & 69.66 & 0.93 & 79.49 & 1.26 & 71.70 \\
\hline $\mathrm{K}$ & 1691 & 16.20 & 0.89 & 40.00 & 7.45 & 96.83 & 2.19 & 97.30 & 2.90 & 97.96 \\
\hline All & 36819 & 17.61 & 2.96 & 70.28 & 8.11 & 85.86 & 8.38 & 35.19 & 4.13 & 72.73 \\
\hline
\end{tabular}

c-section $=$ caesarean section .

by hospitals basis. Next, a non-conditional logistical regression model was used to isolate the effects of the various variables on the incidence of caesarean sections, analysing the statistical association with the odds ratio (OR), accompanied with the corresponding confidence intervals of $95 \%(95 \% \mathrm{CI})$. We used a model with the principal effects of the variables and two way interactions, forcing (enter method) the inclusion of a first block with the principal effects of all the independent variables considered of interest, independently of their statistical significance. Then, the interactions were included with the forward stepwise method, retaining only those which were statistically significant. If two variables interacted significantly, the influence of one on the probability of a caesarean section was modified in function of the other's value, or vice versa. The model's performance was evaluated on the basis of how closely it predicted the results actually observed, following criteria for discrimination (C statistics) and calibration (Hosmer-Lemeshow test).

The above model was used to analyse the hypothetical differences in caesarean rates between hospitals that cannot be explained by differences in obstetric risks. This approach synthesises all of the factors into a single index that represents the expected probability of a caesarean delivery for each mother. This value was used to calculate the expected caesarean

Table 4 Factors associated with caesarean section. Logistics regression

\begin{tabular}{|c|c|c|c|c|c|}
\hline \multirow{2}{*}{$\frac{\text { Variable }}{\text { Day of the week }}$} & \multirow{2}{*}{$\begin{array}{l}\text { Values } \\
\text { Weekend (ref) }\end{array}$} & \multirow{2}{*}{$\begin{array}{r}\text { OR } \\
1\end{array}$} & \multirow[t]{2}{*}{$p$} & \multicolumn{2}{|c|}{$95 \%$ CI OR } \\
\hline & & & & & \\
\hline & Mon-Fri & 1.4 & 0.000 & 1.2 & 1.5 \\
\hline \multirow{2}{*}{ Previous caesarean } & no (ref) & 1 & & & \\
\hline & yes & 29.8 & 0.000 & 25.1 & 35.4 \\
\hline \multirow[t]{2}{*}{ Admission } & Emergency (ref) & 1 & & & \\
\hline & Programmed & 3.0 & 0.000 & 2.2 & 4.2 \\
\hline Prepartal stay in days & & 1.0 & 0.001 & 1.0 & 1.1 \\
\hline \multirow[t]{2}{*}{ Charlson Index } & 0 (ref) & 1 & & & \\
\hline & 1 or more & 1.7 & 0.008 & 1.2 & 2.6 \\
\hline \multirow{2}{*}{ Multiple birth } & no (ref) & 1 & & & \\
\hline & yes & 3.1 & 0.000 & 2.4 & 4.0 \\
\hline \multirow[t]{3}{*}{ Weight at birth } & $2.5-4.0 \mathrm{~kg}$. (ref) & 1 & & & \\
\hline & $<2500 \mathrm{~g}$ & 2.3 & 0.000 & 1.7 & 3.1 \\
\hline & $>4000 \mathrm{~g}$ & 1.3 & 0.150 & 0.9 & 2.0 \\
\hline \multirow{6}{*}{ Maternal-fetal risk } & None (ref) & 1 & & & \\
\hline & Breech presentation & 744.5 & 0.000 & 452.6 & 1224.9 \\
\hline & Dystocia & 962.5 & 0.000 & 611.9 & 1514.0 \\
\hline & Fetal distress & 119.1 & 0.000 & 80.4 & 176.6 \\
\hline & Other complications & 59.5 & 0.000 & 36.3 & 97.6 \\
\hline & Remainder abnormal births & 16.1 & 0.000 & 12.0 & 21.5 \\
\hline Age $^{\star}$ & $26-34^{\star}$ breech & 0.3 & 0.000 & 0.2 & 0.6 \\
\hline \multirow{8}{*}{ Maternal-fetal risk } & $26-34^{\star}$ dystocia & 0.4 & 0.000 & 0.2 & 0.6 \\
\hline & $26-34^{\star}$ fetal distress & 0.4 & 0.000 & 0.3 & 0.6 \\
\hline & $26-34^{\star}$ other complications & 0.4 & 0.000 & 0.2 & 0.7 \\
\hline & $26-34^{\star}$ r. ab. births & 0.7 & 0.009 & 0.5 & 0.9 \\
\hline & $>34^{\star}$ breech & 0.2 & 0.000 & 0.1 & 0.3 \\
\hline & $>34^{\star}$ dystocia & 0.3 & 0.000 & 0.2 & 0.4 \\
\hline & $>34^{\star}$ fetal distress & 0.3 & 0.000 & 0.2 & 0.5 \\
\hline & $>34^{\star}$ other complications & 0.5 & 0.003 & 0.3 & 0.8 \\
\hline \multirow[t]{5}{*}{ Maternal-fetal risk fetal ${ }^{\star}$ days prepartum } & breech $^{\star}$ days & 1.1 & 0.159 & 1.0 & 1.2 \\
\hline & dystocia $^{\star}$ days & 1.9 & 0.000 & 1.7 & 2.2 \\
\hline & fetal distress ${ }^{\star}$ days & 1.1 & 0.009 & 1.0 & 1.2 \\
\hline & others ${ }^{\star}$ days & 1.4 & 0.000 & 1.2 & 1.5 \\
\hline & rest ${ }^{\star}$ days & 1.1 & 0.002 & 1.0 & 1.2 \\
\hline \multirow[t]{9}{*}{ Maternal-fetal risk ${ }^{\star}$ birth weight } & breech $^{\star}<2500$ & 0.3 & 0.000 & 0.2 & 0.4 \\
\hline & breech $^{\star}>4000$ & 2.0 & 0.251 & 0.6 & 6.2 \\
\hline & dystocia $^{\star}<2500$ & 0.6 & 0.056 & 0.4 & 1.0 \\
\hline & dystocia ${ }^{\star}>4000$ & 0.7 & 0.252 & 0.4 & 1.2 \\
\hline & fetal distress ${ }^{\star}<2500$ & 0.6 & 0.014 & 0.4 & 1.0 \\
\hline & fetal distress ${ }^{\star}>4000$ & 0.6 & 0.059 & 0.3 & 1.0 \\
\hline & others $^{\star}<2500$ & 1.5 & 0.060 & 1.0 & 2.2 \\
\hline & rest ${ }^{\star}<2500$ & 0.6 & 0.002 & 0.4 & 0.9 \\
\hline & r. ab. births ${ }^{\star}>4000$ & 1.4 & 0.222 & 0.8 & 2.3 \\
\hline
\end{tabular}

$\mathrm{n}=35024 ; \chi^{2}(38)=16664.00 ; \mathrm{p}\left(\chi^{2}\right)<0.0001 ; \log$ likelihood $=-7688.62 ; r^{2}=0.52 ; \mathrm{C}$ statistics $=0.94 ;$ ref: reference category; OR: odds ratio; $95 \% \mathrm{CI}$ : confidence intervals of $95 \% .1795$ cases excluded because of missing data in some of the variables used in the model. 
rate for each hospital, based on the distribution in the different hospitals of the known risks. To evaluate the behaviour of the different hospitals, the rates expected were compared with the rates actually observed and contrasted, giving a measurement similar to the relative risk (RR), equal to 1 when there are no differences. To quantify the random error of this $R R$ and establish its confidence intervals, a normal approximation to a binomial distribution ${ }^{14}$ was assumed.

\section{Results}

The rate of caesarean sections for all the hospitals was $17.6 \%$ (table 2). Surgery was the preferred treatment when specific risk factors or circumstances were present during labour (abnormalities in uterine neck, haemorrhaging before birth, dystocia, breech presentation or previous caesarean). In some situations, such as slow uterine growth, chronic or severe maternal hypertension disease, or when the pre-delivery stay had exceeded four days, the probability of caesarean was greater than $40 \%$. Breech presentation accounted for 3\% of births. The incidence of dystocia, without taking into consideration the previous cases, was $8.1 \%$. In the remainder of the deliveries, $8.4 \%$ corresponded to signs of fetal distress. These figures vary considerably from one hospital to another (table 3), particularly in cases of dystocia and fetal distress. The decision to practice a caesarean section in the presence of these risk factors also varied considerably from one hospital to another.

The multivariate analysis showed that maternal-fetal risk factors were strongly associated with the caesarean section (table 4). The diagnosis of breech presentation, dystocia or fetal distress considerably increased the probability of caesarean (OR of 744, 962 and 119, respectively). When non-clinical variables were analysed, the day of the week maintained statistical significance (OR: 1.38, 95\%CI: 1.25 , 1.52), and almost all of the other variables contributed to explaining behaviour during delivery. The interactions between maternalfetal risk factors and age, fetal weight and length of pre-delivery stay were also significant to a similar degree. The interactions between maternal-fetal risk and the first two variables had the effect of lowering the risk of caesarean, while the interaction between maternal-fetal

Table 5 Percentage of caesareans observed and expected by hospitals

\begin{tabular}{lrrrrr}
\hline Hospital & \multicolumn{1}{c}{ Births } & $\begin{array}{l}\text { Caesareans } \\
\text { observed (\%) }\end{array}$ & $\begin{array}{l}\text { Caesareans } \\
\text { expected (\%) }\end{array}$ & $\begin{array}{l}\text { Relative } \\
\text { risk }\end{array}$ & $95 \%$ CI RR \\
\hline A & 2928 & $469(16.01)$ & $456(15.56)$ & 1.03 & $0.97,1.08$ \\
B & 3131 & $456(14.56)$ & $346(11.05)$ & 1.32 & $1.26,1.38$ \\
C & 1817 & $317(17.44)$ & $226(12.45)$ & 1.40 & $1.31,1.49$ \\
D & 13424 & $2593(19.31)$ & $2992(22.28)$ & 0.87 & $0.84,0.89$ \\
E & 1502 & $255(16.97)$ & $163(10.86)$ & 1.56 & $1.47,1.65$ \\
F & 2348 & $359(15.28)$ & $315(13.40)$ & 1.14 & $1.07,1.21$ \\
G & 533 & $130(24.39)$ & $116(21.77)$ & 1.12 & $1.01,1.23$ \\
H & 2391 & $371(15.51)$ & $512(21.42)$ & 0.72 & $0.66,0.78$ \\
I & 1457 & $223(15.30)$ & $244(16.76)$ & 0.91 & $0.84,0.98$ \\
J & 4161 & $613(14.73)$ & $456(10.96)$ & 1.34 & $1.28,1.40$ \\
K & 1332 & $202(15.16)$ & $162(12.12)$ & 1.25 & $1.16,1.34$ \\
Total & 35024 & $5988(17.09)$ & $5988(17.09)$ & - & - \\
\hline
\end{tabular}

The registry number corresponds to the cases with complete information for all the variables of interest; RR: relative risk; $95 \%$ CI: confidence intervals of $95 \% .1795$ cases excluded because of missing data in some of the variables used in the model.
KEY POINTS

- Caesarean section rates in the Valencia Health Service-a public hospital network without economic incentives-has risen from $9.7 \%$ in 1984 to $17.6 \%$ in 1994-95.

- Caesarean section rates, and the indications that lead to caesarean sections, differ considerably from one hospital to another. This variability cannot be explained by differences in obstetric risks in the different centres or by other clinical factors

- The study does not suggest an appropriate rate for caesarean sections, but the wide variability observed, including within each risk category, suggests that caesarean section is often inappropriately used.

- Imprecise diagnosis of dystocia and fetal distress and information biases, limits drawing broad spectrum conclusions from hospital discharge administrative databases.

risk and the length of the pre-birth stay had the opposite effect. A woman presenting these two factors would have a higher than expected risk based on the product of the ORs. The multivariate model was $90.6 \%$ correct in its predictions (cut off point $>0.5$ ), with a sensitivity of $62.6 \%$, specificity of $96.3 \%$, positive prediction value of $77.8 \%$ and negative prediction value of $92.6 \%$. The discrimination capacity was very high (C statistics: 0.95 ), but the Hosmer-Lemeshow test showed deficient calibration, as the model in fact predicted fewer caesareans than those actually performed in the deciles with the lowest probability.

Table 5 shows the number and percentage of births in each of the 11 hospitals, compared with those expected on the basis of the previous model, and the relative risk (RR) of caesarean associated with the hospital. Hospital E, for example, performed caesareans in $17.0 \%$ of the births, compared with the $10.9 \%$ expected according to the logistical model (RR: 1.56; 95\% CI: 1.47, 1.65). In Hospital $\mathrm{H}$, however, $15.5 \%$ of deliveries ended in cesareans, when the expected rate based on the structure of the risk factors in its population was $21.4 \%$ (RR: $0.72 ; 0.66,0.78)$.

\section{Discussion}

This study shows that caesarean section rates continue to rise in Valencia (17.6\% in 1994-95), and that rates, and the indications that lead to caesarean sections differ considerably from one hospital to another. This variability cannot be explained by differences in obstetric risks in the different centres or by other clinical factors, confirming - in a public hospital network without economical incentives-findings published elsewhere in the international literature.

The non-clinical determinants that influence the decision to perform a caesarean include the woman's socioeconomic status, ${ }^{15}$ her expectations and preferences when giving birth, ${ }^{16}$ the 
source of financing, ${ }^{17}$ election of defensive medical practices under the threat of legal action, ${ }^{18}{ }^{19}$ the hospitals' practice style ${ }^{320}$ and whether or not it is a teaching hospital. ${ }^{21}$ Other factors include financial and other incentives ${ }^{22}$ and the availability of technology. Some of the variables contemplated in this study attempted to take these factors into account, although most of them have not been explored in the Spanish context. Elucidating these areas, however, would help us understand the variability in rates detected, and explain the factors underlying the cesarean "epidemic", to which the Spanish National Health System has not been immune.

Today the risks associated with surgery are lower than before. However, as the risk of not performing surgery must be weighed by the healthcare provider who may face complaints or lawsuits if the delivery is unsatisfactory, the true implications in the rise in caesarean section rates need to be clarified. Despite safer surgery, mortality is still much higher after abdominal than vaginal delivery, and given the volume of births, the accumulation of many small risks can result in a significant increase in avoidable maternal deaths. Another factor that cannot be overlooked is maternal morbidity and discomfort post-caesarean. ${ }^{23} 24$

In obstetrics, the need for surgery is often assessed through the ongoing evaluation of risks, and the high caesarean rates seen today may indicate that the methods used to gauge these risks are the wrong ones. In some hospitals, deliveries are managed in the same way for all women, independently of previous risks, with the routine use of techniques with low specificity, such as fetal monitoring. This can lead to the over-identification of signs of fetal distress (false positives), and to unnecessary surgical interventions. ${ }^{25}$

In contrast with previous Spanish studies, ${ }^{9}{ }^{26}$ in this study access to clinical information about each patient made it possible to calculate specific rates for the various risk factors. However, two limitations should be pointed out: the imprecise diagnosis of dystocia and fetal distress, and information biases in the MBDS. In the first instance, because there are no precise criteria to identify dystocia and fetal distress, these risk factors are diagnosed inconsistently, causing the caesarean section rates associated with them to vary considerably. The hospitals examined showed a tendency towards an inverse relation between the incidence of dystocia and fetal distress and the percentage of caesareans. However, exceptions suggest that some hospitals tend to use specific diagnostic categories, and to proceed to surgery after the diagnosis has been established. The second limitation of the study, possible biases in the MBDSs, poses one of the main problems in drawing broad spectrum conclusions from our data. To limit these biases, we opted to exclude seven hospitals furnishing poor quality information, although that made it impossible to extrapolate results to the whole Valencia healthcare system. None the less, it is unlikely that the inclusion of these hospitals would have changed the trends detected, as they showed greater variability than the hospitals included (variation coefficient 0.49 , compared with 0.32 in the hospitals included). However, the estimate of caesarean rates for each hospital based on the average behaviour observed can be biased by the quality of the information in the MBDS. Hence, fewer cases would be expected than those observed in hospitals where risk factors were under-declared.

When assessing the quality of the information on which the study was based, of particular interest is the history of previous caesarean, a highly controversial indication. ${ }^{15} 27$ Studying the cases of the 172 women who, during 1993-95, were known to have given birth for the first time with caesarean section, and who had another child in 1994-95, suggests that this antecedent is under-declared in a systematic and biased manner. The antecedent was recorded for only $53.5 \%$ of the women, and $59.3 \%$ of these patients subsequently had a second caesarean section. However, it is telling to observe that if the antecedent was not available only $46.2 \%$ of these mothers had a second caesarean; if the information was provided the rate of subsequent cesarean was $78.7 \%$.

Although our study does not suggest an appropriate rate for caesarean sections, the wide variability observed, including within each risk category, suggests that surgery is often inappropriately used. The data suggest, above all, that the caesarean is often practised when it is not clearly indicated, although there are probably also instances where surgery should be performed, but is not. These circumstances make it necessary to devise interventions for the selective reduction of caesareans, safeguarding situations where the benefits of surgery outweigh the risks involved. In other countries, intervention has concentrated on three different areas that account for about $75 \%$ of caesareans: previous caesarean delivery, dystocia and fetal hypoxia. Work in this area includes the systematic review of all available evidence and the development of guidelines based on scientific evidence, research to increase the body of available evidence and medical audits or utilisation reviews with feedback to obstetricians. Many of these strategies have proved to be viable and useful in containing and reducing the percentage of caesarean sections, while protecting mother and infant from increases in risks. In the Spanish-and European-context there remains much to be done in many areas: we must continue monitoring the trend, and analyse the factors underlying the variability observed. More importantly, however, we must apply the scientific results available to us to design interventions to improve the use of the caesarean section.

The Dirección para la Gestión de la Atención Especializada del Servei Valencia de la Salut provided the databases used in our purposes in purposes in courses on risk adjustment organiSed by the Valencian Institute for Studies in Public Health, the Universidad Miguel Hernandez and the Universidad Pompeu Fabra, and the final manuscript has benefited from the contributions of
students, particularly specialists in gynaecology and obstetrics. 
Concha Colomer and Laura Fitera have also provided useful comments.

Funding: This study was conducted as part of a research project financed under headings $96 / 1028$ of the Fondo de Investigación fanitaria (FIS) and 068/005/1995 of the Institució Valenciana d'Estudis i Investigaciones (IVEI).

d'Estudis i Investigaciones
Conflicts of interest: none.

1 Notzon FC, Placek PJ, Taffel SM. Comparisons of national cesarean-section rates. $N$ Engl F Med 1987;316:386-9.

2 Sheehan KH. Caesarean section for dystocia: a comparison of practices in two countries. Lancet 1987;i:548-51.

3 Notzon FC. International differences in the use of obstetric Notzon FC. International differences in the
interventions. $¥ A M A$ 1990;263:3286-91.

4 Stephenson PA, Bakoula C, Hemminki E, et al. Patterns of use of obstetrical interventions in 12 countries. Paediatr Perinat Epidemiol 1993;7:45-54.

5 McKenzie L, Stephenson PA. Variation in cesarean section rates among hospitals in Washington State. Am f Public Health 1993;83:1109-12.

6 Porreco RP, Thorp JA. The cesarean birth epidemic: trends, causes, and solutions. Am f Obstet Gynecol 1996;175:36974.

7 Francome C, Savage W. Caesarean section in Britain and the United States $12 \%$ or $24 \%$ : is either the right rate? Soc Sci Med 1993;37:1199-218.

8 Joffe M, Chapple J, Paterson C, et al. What is the optimal caesarean section rate? An outcome based study of existing variation. $\mathcal{F}$ Epidemiol Community Health 1994;48:406-11.

9 Sarria Santamera A, Sendra Gutierrez JM. Evolución de la Sarria Santamera A, Sendra Gutierrez JM. Evolución de la tasa de cesa-14.

10 Instituto Nacional de Estadística. Encuesta de Morbilidad Hospitalaria 1993. Madrid: Instituto Nacional de Estadística, 1993

11 Librero J, Peiró S, Ordiñana R. Chronic comorbidity and outcomes of hospital care: length of stay, mortality and readmission at 30 and 365 days. F Clin Epidemiol 1999;52 $171-9$.

12 Anderson GM, Lomas J. Determinants of the increasing cesarean birth rate. Ontario data 1979-1982. N Engl f Med 1984;311:887-92.
13 Henry OA, Gregory KD, Hobel CJ, et al. Using ICD-9 codes to identify indications for primary and repeat cesarean sections: agreement with clinical records. Am $\mathcal{F}$ Public Health 1995;85:1143-6.

14 Hosmer DW, Lemeshow S. Confidence interval estimates of an index of quality performance based on logistic regression models. Stat Med 1995;14:2161-72.

15 King DE, Lahiri K. Socioeconomic factors and the odds of vaginal birth after cesarean delivery. $\mathscr{F} A M A 1994 ; 272$ :5249.

16 Atiba EO, Adeghe AJ, Murphy PJ, et al. Patients' expectation and caesarean section rate. [Letter]. Lancet 1993;341:246.

17 Bertollini R, DiLallo D, Spadea T, et al. Cesarean section rates in Italy by hospital payment mode: an analysis based on birth certificates. Am f Public Health 1992;82:257-61.

18 Localio AR, Lawthers AG, Bengtson JM, et al. Relationship between malpractice claims and cesarean delivery. $7 A M A$ 1993;269:366-73.

19 Baldwin LM, Hart LG, Lloyd M, et al. Defensive medicine and obstetrics. FAMA 1995;274:1606-10.

20 Rock SM. Variability and consistency of rates of primary and repeat cesarean sections among hospitals in two states. Public Health Rep 1993;108:514-16.

21 Oleske DM, Glandon GL, Giacomelli GJ, et al. The cesarean birth rate: influence of hospital teaching status. Health Serv Res 1991;26:325-37.

22 Keeler EB, Brodie M. Economic incentives in the choice between vaginal delivery and cesarean section. Milbank $Q$ 1993;71:365-404

23 Mutryn CS. Psychosocial impact of cesarean section on the family: a literature review. Soc Sci Med 1993;37:1271-81.

24 Hemminki E. Long term maternal health effects of caesarean section. 7 Epidemiol Community Health 1991;45: $24-8$.

25 Treffers PE, Pel $M$. The rising trend for caesarean birth. BMF 1993;307:1017-18.

26 Villalbi J, Navarro A, Plasencia A. Variabilidad en la práctica de cesárea. Gac Sanit 1995;9:62-3

27 Leyland A. The effect of previous cesarean sections on current cesarean rates. Am f Public Health 1993;83:115-17. 